\title{
PERAN KOMUNIKASI VISUAL INSTAGRAM TERHADAP KEPUTUSAN BERKUNJUNG DI KAWASAN HERITAGE GAJAH MADA DENPASAR
}

\author{
Utik Kuntariati $^{1}$, Ni Made Rinayanthi ${ }^{2}$, Ni Wayan Mega Sari Apri Yani ${ }^{3}$ \\ Institut Pariwisata dan Bisnis Internasional \\ utik.kuntariati@stpbi.ac.id
}

\begin{abstract}
ABSTRAK
Munculnya era tourism 4.0, memberi dampak revolusi industri di sektor pariwisata, ditandai dengan adanya kemudahan akses informasi melalui media digital. Transformasi digital inilah yang mengubah keseluruhan siklus ekosistem kepariwisataan, terutama dari sisi penyebarannya dan konsumsi informasi di media sosial terkait aktivitas berwisata.Tujuan penelitian ini adalah untuk mengetahui bagaimanakah peran komunikasi visual Instagram terhadap keputusan berkunjung ke Kawasan Heritage Gajah Mada Denpasar dan bagaimanakah peran media sosial instagram (partisipasi, keterbukaan dan komunikasi) terhadap keputusan berkunjung ke Kawasan Heritage Gajah Mada Denpasar. Penelitian ini dirancang menggunakan metode kuantitatif dengan analisis korelasi regresi linear berganda. Penelitian ini berfokus pada fenomena sosial dan pada pemberian suara pada perasaan dan persepsi dari informan. Populasi dalam penelitian ini adalah jumlah follower yang diambil dari dua akun Instagram yaitu; @InfoDenpasar sebanyak 879.000 dan@DenpasarTourism sebanyak 2.660 followers, sedangkan dari Tagar (\#), sebanyak 11.002 tags/posts dari \#pasarbadung dan 1000 tags/posts dari \#tukadkorea dengan sampel 155.Hasil penelitian diketahui bahwa tingkat penggunaan sosial media instagram dari karakteristik umum responden ditunjukkan oleh laki-laki dan berumur 17-20 tahun yang mayoritas berdomisili di Bali. Media visual Instagram berpengaruh atau berperan secara nyata terhadap keputusan berkunjung. Berdasarkan analisis kelima dimensi terhadap peran media sosial Instagram yaitu partisipasi, keterbukaan, percakapan, komunitas dan keterhubungan, dimana percakapan, komunitas dan keterhubungan digabung dalam satu dimensi yaitu komunikasi, dimensi komunikasi dan keterbukaan sangat berpengaruh terhadap keputusan berkunjung.
\end{abstract}

Kata Kunci : komunikasi visual; peran Instagram, kawasan heritage.

\begin{abstract}
The emergence of the tourism 4.0 era had an impact on the industrial revolution in the tourism sector, marked by easy access to information through digital media. This digital transformation has changed the entire cycle of the tourism ecosystem, especially in terms of its dissemination and consumption of information on social media related to tourism activities. The purpose of this study was to find out how the role of Instagram visual communication in the decision to visit the Gajah Mada Denpasar Heritage Area and what is the role of social media Instagram (participation, openness and communication) regarding the decision to visit the Gajah Mada Denpasar Heritage Area. This study was designed using quantitative methods with multiple linear regression analysis. This study focuses on social phenomena and on giving a voice to the feelings and perceptions of informants. The population in this study is the number of followers taken from two
\end{abstract}


Instagram accounts, namely; @InfoDenpasar as many as 879,000 and @DenpasarTourism as many as 2,660 followers, while from Tagar (\#), there were 11,002 tags / posts from \#pasarbadung and 1000 tags / posts from \#tukadkorea with a sample of 155. The results showed that the level of use of social media Instagram was from general characteristics respondents indicated by male and aged 17-20 years, the majority of whom live in Bali. Visual media Instagram influences or plays a significant role in visiting decisions. Based on the analysis of the five dimensions of the role of social media Instagram, namely participation, openness, conversation, community and connectedness, where conversation, community and connectedness are combined in one dimension, namely communication, communication dimensions and openness are very influential on visiting decisions.

Keywords: visual communication; role of Instagram, heritage area.

\section{PENDAHULUAN}

Munculnya era tourism 4.0, memberi dampak revolusi industri di sektor pariwisata, ditandai dengan adanya kemudahan akses informasi melalui media digital. Transformasi digital ini yang mengubah keseluruhan siklus ekosistem kepariwisataan, termasuk menjadi penyebab bergesernya budaya siber dan visual pada wisatawan. Dampak pergeseran budaya siber yang terlihat dari transformasi digital pada tourism 4.0 adalah adanya perubahan proses pengambilan keputusan wisatawan. Tipikal budaya siber yang berfokus pada fenomena social and networking (Manovich dalam Macek, 2015), menjadikan media sosial memiliki peran yang signifikan sebagai sumber rujukan wisatawan dalam menentukan tujuan berwisata.

Dalam era tourism 4.0 peran generasi milenial memiliki peran penting, terutama dari sisi penyebaran dan konsumsi informasi di media sosial terkait aktivitas berwisata. Saat ini wisatawan cenderung berkunjung ke sebuah atraksi wisata yang secara visual menyenangkan. Media sosial seperti Instagram membentuk visualisasi seseorang dengan segala aktivitasnya. Media seperti ini dapat membentuk dan membangun pendapat umum dengan cara visualisasi yang baik dan sesuai dengan pengharapan wisatawan (Kertamukti, 2015). Penggunaan media sosial dirasa mudah, hemat biaya dan efektif dalam pemasaran pariwisata bagi suatu daerah, maka hal tersebut yang membuat media sosial semakin diminati untuk sarana komunikasi dan promosi (Gholil dalam Trihayuningtyas, Wulandari, Adriani, \& Sarasvati, 2019).

Menurut Prakoso (2014:67) Instagram adalah media sosial berbasis sharing foto maupun video. Unggahan foto ataupun video dilengkapi dengan caption dan hastag. Caption merupakan informasi mengenai foto maupun video yang telah diunggah, sedangkan hastag merupakan penggolongan tema atau topik, dimana semakin banyak user menggugah maka semakin banyak hastag. Hastag juga digunakan untuk mempermudah user dalam mencari sebuah postingan (Atmoko, 2012:59). Setelah mengunggah foto ataupun video hal yang umum terjadi yaitu followers dapat memberikan like ataupun comment di unggahan tersebut.

Hampir seperempat populasi penduduk Indonesia aktif menggunakan media sosial Instagram. Perusahaan analis Sosial Media Marketing yang berbasis di Warsawa, Polandia, NapoleonCat mencatat dengan jumlah penggunaan Instagram Indonesia per November 2019 yakni sebanyak 61.610.000 juta (Hamdan, 
2019). Komunikasi merupakan hal yang sangat penting bagi kehidupan manusia. Komunikasi bisa dalam bentuk verbal maupun non-verbal. Jika dalam bentuk verbal; menggunakan kata-kata yang disusus menjadi kalimat, non-verbal bisa dalam bentuk bahasa tubuh maupun gambar atau foto.

Komunikasi visual bahasa inilah yang disebut piktograf, yaitu bahasa yang menggunakan simbol-simbol. Selain itu juga terdapat bentuk komunikasi visual yang lain disebut hieroglyphics. Hieroglyphics merupakan gambar-gambar atau simbol-simbol sebagai penanda suatu kejadian atau sebagai tata cara mereka berkomunikasi dengan kelompok. Seiring dengan kemajuan zaman dan peradaban manusia, bentuk-bentuk tersebut beralih ke verbal atau tulisan seperti prasasti, buku, dan lain-lain. Sehingga, bentuk tulisan pun kini semakin berkembang juga karena adanya kreativitas seseorang yang semakin maju. Bentuk tulisan ini pun menjadi bentuk komunikasi yang lebih komunikatif dan efektif dibandingkan sebelumnya.

Kawasan heritage Gajah Mada Denpasar merupakan representasi dari kota tua Denpasar saat ini. Kawasan ini dilatar belakangi bangunan tua yang difungsikan sebagai pertokoan. Jajaran pertokoan di kawasan heritage Gajah Mada ini menunjukkan kejayaan kawasan sebagai pusat perdagangan terbesar di Kota Denpasar hingga saat ini. Kawasan heritage memberikan suatu persepsi yang berkorelasi dengan nilai sejarah kawasan. Nilai sejarah menjadi ciri khas atas keunikan kawasan tersebut dan mempengaruhi perkembangan fisik kota pada umumnya. Peradaban masa lalu kota menjadi daya tarik tersendiri (Entas \& Widiastiti, 2018).

Berdasarkan latar belakang berkembangnya kawasan heritage Gajah Mada, maka dilakukan penelitian dengan judul "Peran Komunikasi Visual Instragram terhadap Keputusan Berkunjung Wisatawan Di Kawasan Heritage Gajah Mada Denpasar" dengan rumusan masalah yaitu :

1. Bagaimanakah peran komunikasi visual Instagram terhadap keputusan berkunjung ke Kawasan Heritage Gajah Mada Denpasar?

2. Bagaimanakah peran media sosial instagram (partisipasi, keterbukaan dan komunikasi) terhadap keputusan berkunjung ke Kawasan Heritage Gajah Mada Denpasar?

Berdasarkan rumusan masalah, tujuan penelitian ini yaitu untuk mengetahui peran komunikasi visual Instagram terhadap keputusan berkunjung ke Kawasan Heritage Gajah Mada Denpasar dan peran media sosial instagram (partisipasi, keterbukaan dan komunikasi) terhadap keputusan berkunjung ke Kawasan Heritage Gajah Mada Denpasar.

\section{METODE PENELITIAN}

Penelitian ini dilaksanakan di jalan Gajah Mada saja karena adanya monumen pada saat memasuki jalan Gajah Mada yang bertuliskan Kawasan Heritage. Kawasan Heritage Jalan Gajah Mada ini memiliki lokasi strategis. Selain berada di pusat kota, juga diapit oleh dua pasar tradisional terbesar di Kota Denpasar, yakni Pasar Seni Kumbasari berlokasi di sebelah Barat dan sisi sebelah Timur Pasar Badung.

Penelitian ini dirancang menggunakan metode kuantitatif dengan analisis korelasi regresi linear berganda. Penelitian ini berfokus pada fenomena sosial dan pemberian suara pada perasaan dan persepsi dari informan. Pada tahap awal 
penelitian ini dilakukan perencanaan, selanjutnya pelaksanaan penelitian dengan melakukan observasi, wawancara tidak langsung di dalam kuesioner. Data penelitian yang sudah terkumpul dianalisis, diklasifikan dan dipilih berdasarkan permasalahan yang dikaji. Tahapan kedua adalah penyajian data yang dilakukan dalam bentuk gambar dan narasi, tahapan ketiga adalah penarikan kesimpulan dari hasil penelitian.

Populasi dalam penelitian ini adalah jumlah followers yang diambil dari dua akun Instagram yaitu; @InfoDenpasar sebanyak 879.000 dan @DenpasarTourism sebanyak 2.660 followers, sedangkan dari Tagar (\#), sebanyak 11.002 tags/posts dari \#pasarbadung_dan 1000 tags/posts dari \#tukadkorea. Penelitian ini menggunakan 155 sample, jadi diatas sample minimal yang ditentukan oleh Slovin.

Jenis data yang digunakan dalam penelitian ini adalah kualitatif dan kuantitatif. Data kualitatif adalah data yang bersifat verbal, berupa opini, teks, dan wacana, gambar dan lain-lain yang diperoleh dari observasi dan analisa dokumen, sedangkan data kuantitatif adalah data-data yang berupa angka-angka dan dihitung menggunakan statistik deskriptif sederhana, dalam bentuk persentase dan penentuan jawaban tertinggi. Sumber data primer berupa hasil kuesioner dengan para pengunjung Kawasan Heritage Gajah Mada. Data sekunder diperoleh dari kepustakaan seperti artikel dan gambar yang dimuat dalam media cetak maupun foto yang dimuat di sosial media Instagram. Metode pengumpulan data yang digunakan dengan membagikan kuesioner kepada wisatawan.

Informan dalam penelitian ini dipilih dengan teknik purposive sampling. Purposive sampling adalah teknik penentuan sampel dengan pertimbangan tertentu (Sugiyono, 2009). Alasan pemilihan sampel dengan menggunakan purposive sampling karena tidak semua sampel memiliki kriteria yang sesuai dengan penulis tentukan. Untuk kriteria yang dijadikan informan adalah wisatawan yang berumur dari 17 tahun hingga 30 tahun. Dengan demikian diharapkan dapat diperoleh informasi secara menyeluruh terkait dengan tema penelitian yang dibahas.

Dalam penelitian ini, kesungguhan responden dalam menjawab pertanyaan kuesioner merupakan hal yang sangat penting, karena keabsahan (validitas) suatu hasil, penelitian sangat ditentukan oleh alat pengukur instrumen yang digunakan dalam data yang diperoleh. Berdasarkan pertimbangan tersebut dalam penelitian ini dilakukan pengujian apakah instrumen dan data penelitian berupa jawaban responden telah dijawab dengan benar atau tidak. Pengujian tersebut meliputi pengujian validitas dan pengujian reliabilitas. Untuk keperluan analisis uji validitas dan reliabilitas data serta untuk uji analisis regresi linier berganda maka skala likert diubah menjadi skala interval dengan MSI (Measure Succesive Interval) dengan program STAT 97.XLA.

\section{HASIL DAN PEMBAHASAN}

Berdasarkan hasil analisis peneliti dapat diketahui bahwa tingkat penggunaan media sosial Instagram dari karakteristik umum responden ditunjukkan oleh laki-laki sebesar 60\% dan berumur 17-20 tahun sebanyak 79,4\% yang mayoritas berdomisili di Bali (94,6\%). Media visual Instagram (X) berpengaruh atau berperan secara nyata terhadap keputusan berkunjung (Y) ditunjukkan dengan $\mathrm{F}$ hit $=87.286$ dengan signifikansi $0,000<0,01$ yang berarti sangat signifikan. 
Dari tanggapan responden terhadap kelima dimensi sosial media yaitu partisipasi (X1), keterbukaan (X2), percakapan, komunitas dan keterhubungan, dimana percakapan, komunitas dan keterhubungan digabung dalam satu dimensi yaitu komunikasi (X3), dimensi komunikasi (X3) dan keterbukaan (X2) sangat berpengaruh terhadap keputusan berkunjung yaitu dengan prosentase sebesar 43,1\% dimana sisanya sebesar $56,9 \%$ dipengaruhi oleh variabel lain.

Dari kelima dimensi tersebut di atas hanya satu dimensi yang tidak berpengaruh terhadap keputusan berkunjung, yaitu dimensi partisipasi (X1) karena nilai t hit $=1,436$ dengan signifikansi $=0,153>0,025$ non signifikan sehingga ini menunjukkan bahwa dimensi partisipasi tidak berpengaruh terhadap keputusan berkunjung karena parsial korelasi yang rendah yaitu 0,0116 .

Hasil dari penelitian ini sesuai dengan penelitian serupa yang dilakukan oleh Adinda dan Pangestutu (2019) dengan judul "Pengaruh Media Sosial Instagram@exploremalang Terhadap Minat Berkunjung Followers Ke Suatu Destinasi (Survey Pada Followers @exploremalang”, dimana hasil dari penelitian tersebut menyatakan bahwa media sosial Instagram mempunyai pengaruh yang signifikan terhadap minat berkunjung followers ke suatu destinasi wisata. Begitu juga dengan penelitian yang dilakukan oleh Priatmoko (2017) dengan judul "Pengaruh Atraksi, Media Sosial, dan Infrastuktur Terhadap Keputusan Berkunjung Wisatawan ke Desa Wisata Pentingsari Yogyakarta". Hasil penelitian tersebut juga menyatakan bahwa variabel media sosial berpengaruh paling dominan terhadap keputusan berkunjung wisatawan.

\section{SIMPULAN}

Berdasarkan hasil analisis dan pembahasan data peran komunikasi visual media sosial Instagram terhadap responden diketahui bahwa tingkat penggunaan sosial media instagram dari karakteristik umum responden ditunjukkan oleh lakilaki dan berumur 17-20 tahun yang mayoritas berdomisili di Bali. Media visual Instagram berpengaruh atau berperan secara nyata terhadap keputusan berkunjung. Berdasarkan analisis kelima dimensi terhadap peran media sosial Instagram yaitu partisipasi, keterbukaan, percakapan, komunitas dan keterhubungan, dimana percakapan, komunitas dan keterhubungan digabung dalam satu dimensi yaitu komunikasi, dimensi komunikasi dan keterbukaan sangat berpengaruh terhadap keputusan berkunjung.

\section{SARAN}

Adapun saran yang dapat diberikan peneliti berdasarkan hasil pembahasan dan simpulan yang diperoleh adalah sebagai berikut:

1. Bagi Dinas Pariwisata Kota Denpasar terutama kepada pengelola akun-akun sosial media instagram khususnya@denpasartourism dan@infodenpasar agar mendapatkan perhatian lebih. Supaya akun tersebut dapat digunakan oleh wisatawan sebagai referensi dalam mencari destinasi wisata yang ada di kota Denpasar. Pengelola akun sosial media juga harus dapat memberikan berita terbaru, informasi terbaru agar dapat mempermudah para wisatawan lokal atau domestik dalam mengakses informasi mengenai destinasi wisata melalui sosial media Instagram sebelum mereka melakukan perjalanan wisata. 
2. Bagi peneliti selanjutnya agar dapat meningkatkan keputusan berkunjung ke Kawasan Heritage karena dalam penelitian ini peneliti hanya membahas wisatawan yang sudah berkunjung ke Kawasan tersebut dan sudah mempostingnya dibeberapa taggar seperti \#tukadkorea dan \#pasarbadung dan kemudian peneliti dapat meneruskan atau mengembangkan penelitian ini dengan mencari faktor lain yang dapat mempengaruhi keputusan berkunjung wisatawan selain sosial media.

\section{DAFTAR PUSTAKA}

Adinda, S., \& Pangestutu, E. (2019). Pengaruh Media Sosial Instagram @exploremalang Terhadap Minat Berkunjung Followes Ke Suatu Destinasi. Jurnal Administrasi Bisnis, $72(1)$.

Atmoko, B. D. (2012). Instagram Handbook. Jakarta: Gramedia Pustaka Utama.

Entas, D., \& Widiastiti. (2018). Kawasan Heritage jalan Gajah Mada Sebagai Upaya Pelestarian Kawasan Kota Tua Denpasar Bali. Jurnal Industri Pariwisata, 1(1).

Hamdan, N. (2019). Pengguna Instagram di Indonesia Terbesar ke-4 Dunia. Retrieved from Tagar website: https://www.tagar.id/pengguna-instagram-di-indonesia-terbesar-ke4dunia

Kertamukti, R. (2015). Strategi Kreatif Dalam Perikalanan. Jakarta: PT Raja Grafindo Persada.

Macek, J. (2015). Social Media and Diffused Participation. In P. Lorentz, D. Smahel, M. Metykova, \& M. Wright (Eds.), Living In The Digital Age: Self-Presentation, Networking, Playing, And Participating In Politics. Brno: Masaryk University Press.

Prakoso, A. (2014). Mobile Mantra Uang. Jakarta: Gramedia Widiasarana Indonesia.

Priatmoko, S. (2017). Pengaruh Atraksi, Media Sosial, dan Infrastruktur Terhadap Keputusan Berkunjung Wisatawan Ke Desa Wisata Pentingsari Yogyakarta. Jurnal Khasanah Ilmu, 8(1).

Sugiyono. (2009). Metode Penelitian Kuantitatif, Kualitatif dan R\&D. Bandung: Alfabeta.

Trihayuningtyas, E., Wulandari, W., Adriani, Y., \& Sarasvati, S. (2019). Media Sosial Sebagai Sarana Informasi Dan Promosi Pariwisata Bagi Generasi Z Di Kabupaten Garut. Tourism Scientific Journal, 4(1), 1. https://doi.org/10.32659/tsj.v4i1.46 